\title{
Technical caveats in salvage robot assisted radical prostatectomy
}

\author{
Ashwin Tamhankar ${ }^{1}$, Alexander Hampson ${ }^{2}$, Nikhil Vasdev ${ }^{3,4}$ \\ ${ }^{1}$ Department of Urology, Hertfordshire and Bedfordshire Urological Cancer Centre, East and North Hertfordshire NHS Trust, UK; ${ }^{2}$ Department \\ of Urology, East and North Hertfordshire NHS Trust, UK; ${ }^{3}$ Urological Cancer Centre, Lister Hospital, Stevenage, UK; ${ }^{4}$ School of Life and Medical \\ Sciences, University of Hertfordshire, Hatfield, UK \\ Correspondence to: Dr. Ashwin Tamhankar, Senior Robotic Fellow, Ashwell 1, East and North Herts NHS Trust, Lister Hospital, Stevenage, SG14FG, \\ UK. Email: ashwintamhankar@gmail.com.
}

Submitted May 27, 2020. Accepted for publication Sep 18, 2020.

doi: $10.21037 /$ tau-20-949

View this article at: http://dx.doi.org/10.21037/tau-20-949

Salvage robot assisted radical prostatectomy (RALP) is a therapeutic challenge with higher complication rates. Moreover, it is quite underutilised even in high volume centres till date which is as low as 3\% (1). The reason for the same being higher chances of intra-operative complications and anastamotic leak requiring prolonged catheterisation (1). Long term consequences would be incontinence, as continence rates vary between $36-81 \%$ (2). In the current era of minimal invasive surgeries, this certainly is a daunting task and needs adequate expertise to produce acceptable results. This is a video demonstration highlighting the step by step approach for salvage RALP performed in one of the high volume centres for robotic surgeries in urology (Video 1).

There are certain technical nuances in salvage setting which involve consideration of proper consent for the patient which would include possible colostomy and open conversion. A flexible cystoscopy with dilatation of urethra is advisable at the beginning as there is a high likelihood of having a subtle stricture in bulbar urethra as a consequence of radiation. Certain steps need careful assessment in particular which would include initial evaluation of a plane between the Denonvillier's fascia and the prostate and seminal vesicles. It is advisable to evaluate this plane before committing to the non reversible steps of the procedure. In centres where anterior approach is practised, this stands as one of the indications for performing the posterior dissection in the beginning of the procedure. Bladder neck sparing is possible by meticulous dissection of endopelvic fascia and bladder neck identification which is crucial to have relatively better continence in recovery.
Circumferential dissection around the bladder neck gives extra edge for the sparing as depicted in the video (Figure 1). For achieving maximal urethral length, apical dissection needs to be done with utmost precaution. Vessel sealer acts as an important tool in these cases for simultaneous dissection and haemostasis. It helps in taking control of the pedicles in a better manner as the application of locking clips is challenging due to radiation related scarring. It can be very well used as dissector at different steps. The index case is a 70-year-old gentleman who underwent a non nerve sparing salvage RALP for a biopsy proven (Gleason score $3+4$ ) radio-recurrent prostate cancer with a prostate specific antigen (PSA) levels of $9.6 \mathrm{ng} / \mathrm{mL}$. Console time was 120 minutes and patient was discharged in 2 days. Final pathology was pT2cN0M0 with clear margins. In follow up, patient was continent at 6 months with an undetectable PSA levels. In last one year both the cases operated for salvage RALP have done well without any intra-operative or postoperative complications. Both the patients were continent within 6 months and disease free until the longest respective follow up (6 and 10 months).

Salvage RALP is a safe and feasible procedure with encouraging perioperative outcomes especially after gaining adequate experience of robotic pelvic oncology procedures. Background experience of robotic pelvic surgeries is essential before venturing into the armamentarium of salvage RALP. Dissection along the anatomical landmarks is the key. High volume centres should be the referral centres for this procedure. More data needs to be reported especially in this context for informed decision making for the patient. 


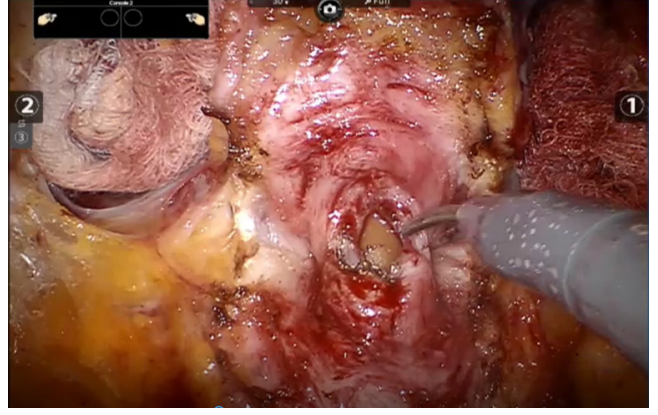

Figure 1 Bladder neck sparing and circumferential dissection.

\section{Acknowledgments}

Funding: None.

\section{Footnote}

Conflicts of Interest: All authors have completed the ICMJE uniform disclosure form (available at http://dx. doi. org/10.21037/tau-20-949). The authors have no conflicts of interest to declare.

Ethical Statement: The authors are accountable for all aspects of the work in ensuring that questions related to the accuracy or integrity of any part of the work are appropriately investigated and resolved. All procedures performed in studies involving human participants were in accordance with the ethical standards of the institutional and/or national research committee(s) and with the Helsinki Declaration (as revised in 2013). Written informed consent was obtained from the patient.

Open Access Statement: This is an Open Access article distributed in accordance with the Creative Commons Attribution-NonCommercial-NoDerivs 4.0 International License (CC BY-NC-ND 4.0), which permits the noncommercial replication and distribution of the article with the strict proviso that no changes or edits are made and the original work is properly cited (including links to both the formal publication through the relevant DOI and the license). See: https://creativecommons.org/licenses/by-nc$\mathrm{nd} / 4.0 /$.

\section{References}

1. Clery R, Grande P, Seisen T, et al. Outcomes after salvage radical prostatectomy and first-line radiation therapy or HIFU for recurrent localized prostate cancer: results from a multicenter study. World J Urol 2019;37:1491-8.

2. Rosoff JS, Savage SJ, Prasad SM. Salvage radical prostatectomy as management of locally recurrent prostate cancer: outcomes and complications. World J Urol 2013;31:1347-52.

Cite this article as: Tamhankar A, Hampson A, Vasdev N. Technical caveats in salvage robot assisted radical prostatectomy. Transl Androl Urol 2020;9(6):2862-2863. doi: 10.21037/tau-20-949 